\title{
Overdue: another scientific revolution
}

\author{
J. Tuzo Wilson, Director General of the Ontario Science Centre in \\ Toronto, argues the case for a return from growth to stability
}

CERTAIN major turning points in the history of science can be called scientific revolutions. Their influence is not confined to science, for they have solved philosophical puzzles and changed economies, but their importance warrants a search for new revolutions. It might be fruitful: history shows that earlier scientific revolutions have cast their shadows before them and have progressed through several parallel stages.

Before each of the past revolutions, for example, their old theories worked well and were useful. Their value has been partly hidden by subsequent attempts to denigrate them: before Copernicus, Ptolemaic astronomers had invented the calendar, predicted eclipses and acted as navigators for Columbus and Magellan; biology, classical physics and geology were similarly useful and well-developed sciences, even before the revolutionary discoveries of Darwin, Becquerel and Wegener. The triumph of each of the new theories was due to important new discoveries, observations or ideas which the old theories could not explain, as the observation of the phases of Venus, the discovery of radioactivity and realisation of the significance of mid-ocean ridges and paleomagnetism all demonstrate.

In each case the great event marking the revolution revealed contradictions and introduced problems which the old theory could not resoive, leading to a period of confusion. For the most part it was not experts but rebels, outsiders and interlopers from other fields of science who suggested the need for a revolution and produced the evidence supporting it. Thus most geologists continued to oppose the concept of continental drift long after Wegener (a meteorologist) had championed it, after physicists had provided key evidence supporting it and after many of the public had accepted it.

So, far from welcoming the new ideas, the establishment, who had the most to lose, clung for as long as possibie to the old, justifying their position by questioning the new data, discrediting those who advanced them, and trying to patch up the old theories. In these endeavours they frequently found themselves supporting quite illogical positions. Before each revolution was accepted, the state of the subject had become chaotic, but each solved many problems so that the ensuing periods were times of great scientific progress and material benefit.

When one now looks for a field ripe for a scientific revolution the only likely candidate appears to be the marginal science of economic theory. It seems to meet most of the criteria advanced. To the extent that the steady increase in wealth over the past few centuries can be attributed to theory, economic theory can be held to have been successful. But any examination of nature or of primitive societies or any consideration of the mathematical consequences of continuous growth will show that stability is normal and growth abnormal. The history of the West since the Renaissance, and particularly since the start of the Industrial Revolution, has been one of growth. It has made most of us forget that this is unusual and must end.

Now an event has occurred which is so important that it is altering the course which history has maintained for several centuries. The cause of the period of growth and the reason for a delay in fulfilling Malthus' predictions has been that for several centuries energy has become ever more abundant at ever less cost. The oil embargo and the quadrupling of the price of crude oil has ended this period and marks a turning point in history. Some say we must seek substitutes. This is not as important as many seem to think, because many are already available. What is needed is the recognition that no substitutes, either known or awaiting discovery, are at all likely to be so cheap. It seems probable that holes drilled in the ground to produce petroleum have been cheaper than any mines, factories or collecting devices which can be built to generate other forms of power are likely to be.

But matters go further. The old system has broken down. There is a recession from which economies are not emerging as the old cyclical pattern predicted. There is unemployment coupled with inflation. In addition, many organisations and individual members of the general public since Malthus have recognised the coming breakdown, seen that growth can only be temporary, and predicted change. It is not right to say that history has proved Malthus wrong. Fundamentally his ideas were correct, but living in the eighteenth century he did not see that development of power from steam, electricity and internal combustion engines and the whole industrial revo- lution would delay their impact.

Moreover, the establishment, blind to logic, denigrates those who foresee the inevitability of change as "doomsters", and clings to theories which if they have not broken down completely already are mathematically certain to do so before long. The differences between those who advocate growth and those who predict no-growth is not as great as might be imagined. The supposed economic experts all demand a return as quickly as possible to an annual rate of growth of, say, $5 \%$. Politicians, businessmen and labour leaders all say that this can be attained. and they well may be right for the next year or two, which is as far as they look ahead, to the next election, next meeting of shareholders, or next signing of a union contract.

On the other hand, any accountant can calculate that an increase in demand of $5 \%$ annually will in thirty years produce more than a fourfold increase in demand. Thirty years is a period most people can expect to see. and one for which young people make plans, but a fourfold increase in demand is ridiculous in face of present shortages. Thus the position held by the present ruling establishment, as has happened in past revolutions, has become untenable. As an example, I was astonished that an influential man to whom I advanced these views replied that they could not be right because if true they would ruin business!

It will be difficult to convince businessmen, who for several centuries have flourished upon growth, that growth cannot long continue. It will be particularly distressing to them because in the past the declining cost of energy has rewarded innovation with profit, so that greed overcame man's natural lassitude and aversion to change. Each change-from slaves to animal power, from windpower to steam and from steam to internal combustion enginesincreased profits.

In future the changes to more expensive forms of power will decrease profits and this is producing a tendency to cling to existing practices. If supplies become exhausted before this is overcome and adequate replacements made, breakdown and anarchy are likely to result. Therefore it is vital to prepare for a return to a stable society and not fritter away resources which are still available to us trying to stimulate growth when the means to support growth are no longer going to be available.

For each past revolution, however, recognition of the new theory has 
always made progress possible again. Even after it has bcen recognised that we must accept an overall economy which is less lavish than before, great rebuilding will be needed. As the supplies of oil and gas run out the whole petroleum industry, for example, will have to be replaced by other industries, ultimately by ones that depend upon renewable resources. We have seen many such changes, for example the change over the past 50 years from coal to oil. These changes involve work and employment.

No growth overall need not mean overall stagnation once the correct direction is recognised and followed. Undisturbed Nature is stable, but it is certainly active. I therefore prefer the term renewal economy to no-growth society. The best chance to avoid ultimate breakdown and anarchy and to maintain any of the present forms of society is to take steps at once to change them. It should be noted that the change in philosophy must be farther reaching than a mere change between one or another existing political party or between a planned society and free enterprise. All the present economic philosophics ignore Nature's and mathematics' edict that growth cannot continue indefinitely. If some extreme governments have achieved conditions of no growth in their countries it is because of their ineptitude, not their desire.

The need is imperative to recognise and to start to implement this great revolutionary return from growth to stability. Its effects are likely to be more traumatic than those of any previous scientific revolution, but can best be ameliorated by early recognition and acceptance. Nearly three years have already passed since the revolutionary turning point in the availability of energy occurred. It is ironic that it would appear that it is the conservative blindness of those who should be leaders, whether in politics, business, or labour, that is the greatest impediment to advance.

\section{Space: a new phase?}

\section{Keith Runcorn and Paul Coleman describe plans for a major new effort in exploration and urge more European cooperation}

THE landings of Viking spacecraft on Mars on July 20 and September 4. 1976, and of Venera 9 and 10 on the surface of Venus in 1975, mark the culmination of a period of lunar and planetary exploration. Over the past decade manned Apollo landings and the unmanned Ranger, Surveyor, and Luna 16, 20 and 24 landings have been made on selected sites on the Moon. From the data collected on all these remarkable missions, our understanding of the evolution and present state of the Moon and planets is developing at an unprecedented rate. The next decade will see a revolution in our knowledge of the solar system comparable with those studies of continental drift and plate tectonics which, over the past two decades, have transformed our understanding of the Earth.

Europe, with a combined gross national product greater than that of the USA and the Soviet Union, has not so far taken a role which reflects its strength in this field, one of mankind's greatest explorations and scientific endeavours. An opportunity will be afforded by the International Solar System Programme, a project of international collaboration in the exploration of the solar system. The International Council of Scientific Unions recommended last year that all countries should consider how they can most effectively contribute.

Our knowledge of the Moon exceeds

Keith Runcorn is at the University of Newcastle-upon-Tyne. Paul Coleman is at the University of California, Los Angeles. in its detail that of any other body in While it might be feared that sampling the Moon in a restricted number of sites might hopelessly bias our interpretations, it is now clcar that the absence of an atmosphere and an ocean and the weaker tectonic forces than on Earth have resulted in much less segregation and concentration of elements and a much smaller variety of rock strata than on the Earth. This has in turn made it possible for the relatively small number of sampling sites to yield data reasonably representative of the Moon as a whole. On terrestrial planets the solar system except the Earth.

limited samples might not be as successful in determining global properties.

The Moon differentiated about $4.4 \times 10^{4}$ years ago, forming an anorthositic gabbroic crust apparently thicker on the far side than the near side. The sources of the mare basalts. (crystallisation ages 3.2 to $3.8 \times 10^{4}$ years) which filled the great impact hasins left in the Moon after catastrophic bombardment, seem to have differentiated at the same time. The processes that brought about this differentiation are obscure and the depth to which it extended is unknown. If the Moon is found to possess an iron core, this early differentiation must have occurred throughout the Moon. The siderophile and volatile elements on the Moon are depleted relative to the Earth and meteorites: information potentially a key to our understanding of the early evolution and origin of the Moon.

Three entirely unexpected charac-

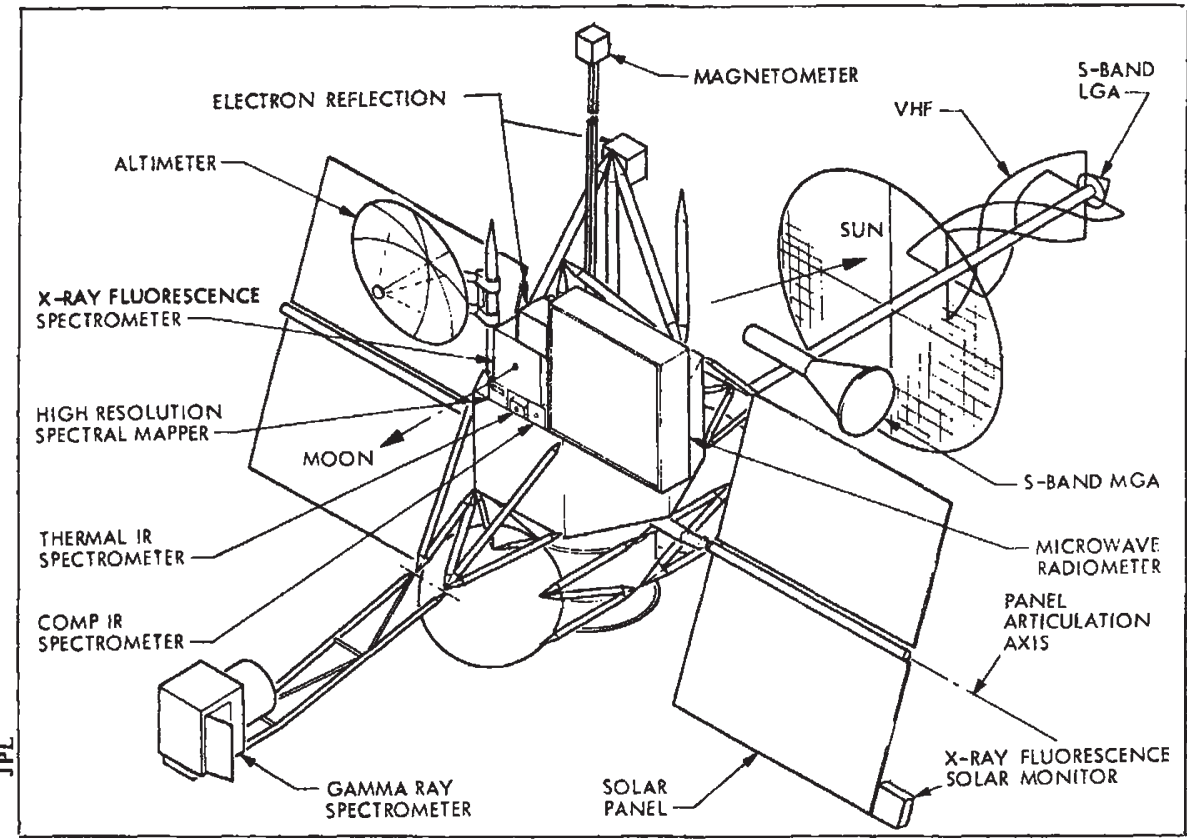

Flight configuration for $T B O L$ 